\title{
Comparative Expression and Cellular Localization of Myo-inositol Phosphate Synthase (MIPS) in the Wild Type and in an EMS Mutant During Common Bean (Phaseolus vulgaris L.) Seed Development
}

\author{
Ghassen Abid • Khaled Sassi • Yordan Muhovski • \\ Jean-Marie Jacquemin • Dominique Mingeot • \\ Neji Tarchoun • Jean-Pierre Baudoin
}

(C) Springer-Verlag 2011

\begin{abstract}
In plants, the myo-inositol-1-phosphate synthase (EC 5.5.1.4; MIPS) is an evolutionarily conserved enzyme protein and catalyzes the synthesis of myo-inositol, which is a central molecule required for cell metabolism and plant growth. A full-length cDNA encoding common bean
\end{abstract}

G. Abid $(\bowtie)$

Centre of Biotechnology of Borj Cedria, Laboratory of Legumes,

University of Carthage,

901 ,

2050 Hammam-Lif, Tunisia

e-mail: gha_abid@yahoo.fr

K. Sassi

National Agronomy Institute of Tunisia (INAT), Department of Agronomy and Plant Biotechnology, Laboratory of Agronomy, University of Carthage,

Avenue Charles Nicolle, 43,

1082 Tunis-Mahrajène, Tunisia

Y. Muhovski $\cdot$ J.-M. Jacquemin $\cdot$ D. Mingeot

Department of Life Sciences, Unit of Breeding and Biodiversity,

Walloon Agricultural Research Centre,

Chaussée de Charleroi, 234,

5030 Gembloux, Belgium

\section{N. Tarchoun}

Unit of Organic and Conventional Vegetable Production,

Agronomic High Institute of Chott Mariem, University of Sousse, 47 ,

4042 Sousse, Tunisia

\section{J.-P. Baudoin}

University of Liège-Gembloux Agro-Bio

Tech. Unit of Tropical Crop Husbandry and Horticulture,

Gembloux Agricultural University,

Passage des Déportés 2,

5030 Gembloux, Belgium
(Phaseolus vulgaris L.) MIPS (designated Pv_BAT93 MIPS) was isolated from seed of $P$. vulgaris (cv, BAT93) by rapid amplification of cDNA ends. The cDNA of Pv_BAT93 MIPS comprised 1,873 bp, which encodes 510 amino acids. The Pv_BAT93 MIPS gene was highly homologous with those of other plant species, such as $P$. vulgaris (cv, Taylor's Horticultural), Arabidopsis thaliana, Medicago sativa and Glycine max. DNA blot analysis indicated that at least three copies of MIPS are present in the common bean genome. RT-PCR analysis indicated that the Pv_BAT93 MIPS transcripts existed in developing seeds and other common bean tissues, including leaves, flowers, and cotyledons but showed lower levels expression in roots and stems. Real-time quantitative PCR showed that Pv BAT93 MIPS gene is differentially expressed during common bean seed development. In situ hybridization of developing seeds in the wild type and in the ethyl methanesulfonate mutant showed that expression of Pv_BAT93 MIPS was identified in the embryo tissues, from the globular to late cotyledon stages, confirming a possible involvement of $\mathrm{Pv}$ _BAT93 MIPS in common bean seed development.

Keywords In situ hybridization $\cdot M y o$-inositol phosphate synthase (MIPS) · Phaseolus vulgaris · RACE · Seed development
Abbreviations
DAP Days after pollination
EMS Ethyl methanesulfonate
MIPS Myo-inositol phosphate synthase
RACE Rapid amplification cDNA ends 


\section{Introduction}

Myo-inositol 1-phosphate synthase (MIPS) catalyses the conversion of D-glucose 6-phosphate (G6P) to myo-inositol 1-phosphate in the presence of the co-enzyme $\mathrm{NAD}^{+}$ (Parthasarathy and Eisenberg 1986), the first committed step in the production of all inositol-containing compounds (Abreau and Aragao 2007) and some other compound involved in the early steps of the phytic acid pathway (Yoshida et al. 2002) which is the most abundant storage of plant seed phosphorus (Larson and Raboy 1999). Myoinositol is the most important and abundant stereoisomer of the six-carbon cyclitol inosito (Luo et al. 2011) and acts as a substrate for the formation of various inositol-derived molecules involved in many different and critical plant biochemical and physiological pathways, such as intracellular signal transduction (Stevenson-Paulik et al. 2005), membrane construction and trafficking (Cullen et al. 2001), and regulation of cell death (Donahue et al. 2010). More recently, myo-inositol was reported to be the main substrate for synthesizing membrane phosphatidylinositol and phosphatidylinositides, which are essential for endomembrane structure and trafficking and thus for auxin-regulated embryogenesis (Luo et al. 2011). The regulation, purification, characterization and localization of MIPS enzymes have been investigated by several authors (Abreau and Aragao 2007; Chiera and Grabau 2007; Mitsuhashi et al. 2008). Two forms of the enzyme have been reported, a cytosolic form and a chloroplastic form. The latter shows enhanced activity during growth in the presence of light (Adhikari et al. 1987). In several species, full-length cDNA sequence encoding a protein with MIPS activity has been isolated and used to study the regulation of inositol biosynthesis. The structural gene coding for MIPS was identified, cloned, sequenced and investigated for a number of higher plants, fungi, animal and algae, including Synechocystis sp. (Chatterjee et al. 2006), Pisum sativum (Imhoff and Bourdu 1973), Vigna radiata (Adhikari et al. 1987; Wongkaew et al. 2010), Oryza sativa (Hait et al. 2002), Glycine max (Iqbal et al. 2002), Citrus paradisi (Abu-abied and Holland 1994), Sesamum indicum (Chun et al. 2003), Arabidopsis thaliana (Johnson 1994), Passiflora edulis (Abreau and Aragao 2007), and Phaseolus vulgaris (Wang and Johnson 1995). Although yeast and animal genomes contain a single gene encoding MIPS (GhoshDastidar et al. 2006; Donahue et al. 2010), plant have multiple MIPS genes (Torabinejads and Gillaspy 2006; Donahue et al. 2010). In common bean, three sequences encoding MIPS gene have been reported: PvMIPSs (GenBank accession AJ853494), expressed mainly in developing seeds; PvMIPSr (GenBank accession U38920), expressed mainly in roots (Wang and Johnson 1995; Johnson and Wang 1996); and PvMIPSv (GenBank accession FN356964), expressed in vegetative organs, especially leaf tissues (Fileppi et al. 2010).

Although MIPS was showed as an important enzyme for inositol and inositol phosphate metabolism in plants, characterization of MIPSs from diverse plant species revealed their important roles in biotic and abiotic stress responses via $\mathrm{Ca}^{2+}$ signaling (Abreau and Aragao 2007). Transcripts encoding MIPS have been shown to be upregulated during salt stress situations (Majee et al. 2004). In common bean, MIPS activity has been reported to be widely distributed in intracellular compartments, including membrane-bound organelles and cell walls, as well as cytoplasm (Lackey et al. 2003). Interestingly, MIPS has also been shown to be highly expressed in developing seeds, suggesting that myo-inositol has an important role in seed development. To date, the localization of the MIPS transcript in developing seed has been characterized only for O. sativa (Yoshida et al. 1999), G. max (Chiera and Grabau 2007), and A. thaliana (Mitsuhashi et al. 2008). In $O$. sativa, in situ hybridization showed that the MIPS (RINO1) transcript appeared initially in the apical region of the embryo and accumulated to a high level in the scutellum and aleurone layers (Yoshida et al. 1999). In G. max, many MIPS isoforms have been shown to be expressed, mainly in developing seeds (Chappell et al. 2006). Hegman et al. (2001) reported that a mutation affecting MIPS expression could be the cause of the low phytate accumulation in the seeds, and mutants were shown to be defective in phytic acid biosynthesis. Defective phytic acid mutant lines from various plant species, including Hordeum vulgare (Hatzack et al. 2000; Dorsch et al. 2003), Zea mays (Raboy et al. 2000), O. sativa (Larson et al. 2000; Kuwano et al. 2006) and G. $\max$ (Wilcox et al. 2000), showed impaired seed development. Similarly, antisense transgenic lines of MIPS genes in Solanum tuberosum plants showed altered plant morphology (Keller et al. 1998). All low phytic acid (lpa) mutants have been shown to be associated with negative effects in terms of seed physiology and plant performance, such as compromised germination and emergence, stress tolerance, and seed filling (Meis et al. 2003; Pilu et al. 2005; Bregitzer and Raboy 2006; Guttieri et al. 2006). More recently, Campion et al. (2009) isolated a P. vulgaris lpa mutant line (lpa-28010) obtained by the chemical mutagenesis (ethyl methanesulfonate) of a lectine-free bean line showing reduced phytic acid, raffinosaccharides and iron cations in the seed compared with the wild type. Unlike other lpa mutants in other species, the bean line (lpa-280-10) mutation does not cause the macroscopic negative effects that adversely influence seed germination, plant growth, seed yield and other traits of genomic relevance (Campion et al. 2009). These authors were not able to determine whether MIPS or any other gene is directly responsible for the observed lpa, 
and did not provide information about the MIPS expression pattern during lpa-280-10 seed development. The disruption of MIPS genes could disturb the normal development of the seeds and lead to embryo abortion in G. $\max$ (Nunes et al. 2006). More recently, the MIPS gene was localized during the early stages of G. max seed development (Chiera and Grabau 2007). In A. thaliana, seed development MIPS cDNA was shown to be expressed exclusively in endosperm tissues (Mitsuhashi et al. 2008). However, little is known about the molecular regulation of MIPS expression in the developing seeds of common bean.

In this paper, we report on the molecular cloning and characterization of the Pv_BAT93 MIPS gene from the common bean using the rapid amplification of cDNA ends (RACE) technique. RT-PCR was performed in order to assess the expression of Pv_BAT93 MIPS in different types of tissues. The expression patterns of MIPS throughout the seed developmental stages were studied using in situ hybridization and real-time quantitative PCR detection in wild-type and ethyl methanesulfonate (EMS) mutant. Our results indicate that MIPS is differentially expressed during common bean seed development and the expression and accumulation of MIPS mRNA is not largely restricted to embryo tissues such as embryo proper as well as in suspensor and cotyledon but is also found in the seed coat outer and inner tegument.

\section{Materials and Methods}

\section{Plant Material}

The common bean mutant was derived from genotypes BAT93 of $P$. vulgaris mutagenized with EMS insertion (Silué et al. 2006). The seeds were imbibed for 3-4 days at $21^{\circ} \mathrm{C}$ in the dark for germination on moistened filter paper in Petri dishes. After radicle emergence, the seedlings were transferred to soil. Plants from common bean wild-type (cv, BAT93) and the EMS mutant were grown under the following climatic conditions in a growth chamber: $27^{\circ} \mathrm{C} / 23^{\circ} \mathrm{C}$ (day/ night) temperature, $75 \%$ relative humidity, $580 \mu \mathrm{E} \mathrm{m}^{-2} \mathrm{~s}^{-1}$ light intensity, and 12-h photoperiod. To harvest seeds of a defined age, individual flowers were tagged with threads on the day of flower opening. P. vulgaris seeds at $3,6,8,9$, and 12 days after pollination (DAP) were isolated from the pods, immediately frozen in liquid nitrogen and stored at $-80^{\circ} \mathrm{C}$. Seeds used for in situ hybridization experiments were isolated from a pod and immersed in fixation solution.

\section{Full-length cDNA Cloning}

Total RNA was extracted from seeds (15 DAP) by the Trizol reagent (Invitrogen), following the manufacturer's protocol, and purified using an RNA/DNA midi kit
(Qiagen). It was then subjected to two rounds of purification using oligo(dT) resin (Qiagen) for enrichment in poly $\left(\mathrm{A}^{+}\right)$RNA. Complementary DNA (cDNA) was synthesized using SMART II A oligo (Clontech) and Power-Script ${ }^{\mathrm{TM}}$ Reverse Transcriptase (Clontech). 5' and 3' RACE were performed using the SMART ${ }^{T M}$ RACE cDNA amplification Kit (Clontech), following the manufacturer's protocol. The gene-specific primer (GSP) for 5' RACE was 5'-AGGTTT GAGGGGCTGAA-3', and for $3^{\prime}$ RACE it was 5'ATCTGGCTATCAGGAGG-3'. The initial PCR was carried out under the following cycling conditions: $3 \mathrm{~min}$ of denaturation at $94^{\circ} \mathrm{C}$, followed by five cycles at $94^{\circ} \mathrm{C}$ for $30 \mathrm{~s}, 65^{\circ} \mathrm{C}$ for $45 \mathrm{~s}$, and $72^{\circ} \mathrm{C}$ for $4 \mathrm{~min}$ and 20 cycles at $94^{\circ} \mathrm{C}$ for $30 \mathrm{~s}, 61^{\circ} \mathrm{C}$ for $45 \mathrm{~s}$, and $72^{\circ} \mathrm{C}$ for $4 \mathrm{~min}$. For the nested RACE reaction, the following program was used: one cycle at $94^{\circ} \mathrm{C}$ for $3 \mathrm{~min}, 30$ cycles at $94^{\circ} \mathrm{C}$ for $30 \mathrm{~s}, 61^{\circ} \mathrm{C}$ for $45 \mathrm{~s}$, and $72^{\circ} \mathrm{C}$ for $4 \mathrm{~min}$ and a final extension at $72^{\circ} \mathrm{C}$ for $10 \mathrm{~min}$ in the iCycler ${ }^{\mathrm{TM}}$ thermocycler (Bio-Rad). PCRs were performed with Platinum Taq High-Fidelity DNA polymerase (Invitrogen).

The resulting PCR products were resolved in a low melting agarose gel, and the appropriate band was excised and purified with the Gene Elute Gel Extraction Kit (Sigma) for the subsequent steps of cloning or sequence determination.

Cloning of Pv_BAT93 MIPS, Detection of Homology, and Sequence Alignment

RACE products were cloned in a pJET1.2/blunt vector using the CloneJETTM PCR Cloning Kit (Fermentas). PCR products $(2 \mu \mathrm{l})$ were added to $2 \times$ reaction buffer (Fermentas), $1 \mu \mathrm{l}$ of the DNA blunting enzyme and incubated at $70^{\circ} \mathrm{C}$ for $5 \mathrm{~min}$. One microliter of the T4 DNA ligase $(5 \mathrm{U} / \mu \mathrm{l})$ and $1 \mu \mathrm{l}$ of the pJET1.2/blunt cloning vector $(50 \mathrm{ng} / \mu \mathrm{l})$ were added to the blunting reaction mixture. This was incubated for $60 \mathrm{~min}$ at room temperature. Four microliters of the reaction were added to one shot of chemically competent Escherichia coli (strain $\mathrm{DH} 5_{\alpha}$ ), and this mixture was incubated by being placed in a $42^{\circ} \mathrm{C}$ water bath for $45 \mathrm{~s}$. Five hundred microliters of LB medium were added to the reaction and shaken at $37^{\circ} \mathrm{C}$ and $220 \mathrm{rpm}$ for $1 \mathrm{~h}$. The cells were then plated on LB medium, which contained ampicilline. These plates were incubated at $37^{\circ} \mathrm{C}$ for at least $24 \mathrm{~h}$ until colonies of cells were observed. The cells were placed in a solution of $2 \mathrm{ml} \mathrm{LB}$ broth with ampicillin $(200 \mathrm{mg} / \mathrm{ml})$ and grown overnight at $37^{\circ} \mathrm{C}$, with shaking at $250 \mathrm{rpm}$.

Plasmids were prepared from positive clones with the Mini Prep Kit (Qiagen) and sequenced with the Thermo Sequenase $^{\mathrm{TM}}$ DYEnamic ${ }^{\mathrm{TM}}$ Direct Cycle Sequencing Kit (GE Healthcare, UK). Pv_BAT93 MIPS sequencing was performed on an LI-COR sequencer (Westburg). Sequence data were analyzed with e-seqV2.0 software. Homology 
between sequences in the GenBank database was detected by using the BLASTX and BLASTN search program provided by the National Center for Biotechnology Information (http://www.ncbi.nlm.nih.gov/BLAST/). Alignment of deduced amino acid sequences was generated by the ClustalW algorithm of sequence analysis software BoSS.

\section{Southern Blot Analysis}

P. vulgaris DNA was prepared from leaves as described by Murray and Thompson (1980). Ten micrograms of genomic DNA were digested with EcoRI, HindIII, or XbaI (Fermentas), separated on a $0.8 \%(w / v)$ agarose gel, and blotted overnight on to Hybond- $\mathrm{N}^{+}$nylon membranes (Amersham Pharmacia Biotech). Blots were hybridized with a probe corresponding to a 484-bp fragment of the Pv_BAT93 MIPS cDNA (from base 954 to 1,438 ) prepared by random priming (Megaprime DNA labeling system; GE, Healthcare, UK) with ${ }^{32} \mathrm{P}-\mathrm{dCTP}$. Hybridization was performed at $37^{\circ} \mathrm{C}$ in $5 \times \mathrm{SSC}, 5 \times$ Denhard's solution, $0.2 \mathrm{mg} / \mathrm{ml}$ sheared denatured salmon testes DNA, $0.005 \mathrm{M}$ phosphate buffer; PH 7 and $0.2 \%$ SDS. Blots were washed three times for $25 \mathrm{~min}$ at $65^{\circ} \mathrm{C}$ with 2,1 , and $0.1 \times \mathrm{SSC}$ with $0.1 \%(w / v)$ SDS at $65^{\circ} \mathrm{C}$, and then autoradiographed using a KODAK Storage Phosphor Screen (Bio-RAD) and an intensifying screen with PERNONAL MOLECULAR IMAGER FX (Bio-RAD).

\section{RT-PCR Expression Analysis}

Total RNA was extracted from frozen P. vulgaris seeds 15 DAP, as well as leaves, roots, stems, cotyledons, and flowers, using Trizol reagent (Invitrogen), following the manufacturer's protocol. For RT-PCR, $10 \mu \mathrm{g}$ of total RNA was treated with $50 \mathrm{U}$ of DNAse I (Fermentas) for $30 \mathrm{~min}$ at $37^{\circ} \mathrm{C}$. The RNA was then precipitated $(0.1$ volume $5.2 \mathrm{M}$ $\mathrm{NH}_{4} \mathrm{OAC}, 2$ volumes ethanol) at $-80^{\circ} \mathrm{C}$ for $1 \mathrm{~h}$. The RNA pellet was re-suspended in $20 \mu \mathrm{l}$ RNase free water and quantified with spectrophotometer.

Total pre-treated RNA $(5 \mu \mathrm{g})$ was reverse transcribed with the RevertAid ${ }^{\mathrm{TM}}$ H Minus First Strand cDNA Synthesis Kit (Fermentas) using an oligo $(\mathrm{dT})_{18}$ primer. The $\mathrm{Pv} 18 \mathrm{~S}$ gene was used as an internal control. Primer pairs were designed by Primer3 Input (version 0.4.0) software (Rozen and Skaletsky 2000; http://frodo.wi.mit.edu/primer3/) and were as follows: for Pv_BAT93 MIPS F5'-GATTTGGCTATCAG GAGG-3' and R5'-AGGTTTGAGGGGCTGAAA-3'; for Pv MIPSs F5'-AATGACACCACGGAGAACCT-3' and R5'CGCAACGTAAGGCACATACT-3'; and for Pv 18S F5'TCGAAGCGATCTTTTCGTAGA-3' and R5' TTCTCAGTCGACTCGCTTTTT-3'. PCR reactions were performed using $0.2 \mathrm{mM}$ of each $\mathrm{dNTP}$ and $0.04 \mathrm{mM}$ of each primer in a final volume of $30 \mu$. The reaction mixtures were heated to $94^{\circ} \mathrm{C}$ for $3 \mathrm{~min}$, followed by 30 cycles of $94^{\circ} \mathrm{C}$ for $30 \mathrm{~s}, 57^{\circ} \mathrm{C}$ for $45 \mathrm{~s}$, and $72^{\circ} \mathrm{C}$ for $1 \mathrm{~min}$. Reactions were completed by incubating at $72^{\circ} \mathrm{C}$ for $10 \mathrm{~min}$. The experiments were repeated three times. The amplified PCR products $(15 \mu \mathrm{l})$ were electrophoresed on a $1 \%(w / v)$ agarose gel, stained with ethidium bromide and scanned using an image analyzer.

\section{Real-time Reverse Transcriptase}

Total RNA isolated from seed tissues $(3,6,8,9$, and 12 DAP) was treated with DNAse I (Fermentas) to remove potential genomic DNA contamination. Five micrograms of DNA-free total RNA was then used to synthesize firststrand cDNAs with the First Strand cDNA Synthesis Kit for RT-PCR (AMV; Roche). The expression of Pv_BAT93 MIPS gene was normalized to the housekeeping gene 18S. Real-time PCR reactions were performed using the ABI7500 FAST real-time PCR instrument (Applied Biosystems). The forward primer for Pv_BAT93 MIPS was 5'GATTTGGCTATCAGGAGG- ${ }^{\prime}$ and for the reverse primer it was $5^{\prime}$-AGGTTTGAGGGGCTGAAA-3'. PCR was conducted in $20 \mu$ of reaction volume containing $10-\mu$ l SYBR Green mix (Fermentas), $0.1 \mu \mathrm{M}$ of each primer and $4 \mu \mathrm{l}$ of cDNA template under the following conditions: $94^{\circ} \mathrm{C}$ for $3 \mathrm{~min}$ and 40 cycles of $94^{\circ} \mathrm{C}$ for $30 \mathrm{~s}, 59^{\circ} \mathrm{C}$ for $45^{\circ} \mathrm{C}$, and $72^{\circ} \mathrm{C}$ for $1 \mathrm{~min}$. PCR was repeated three times for each tested tissue, and mean values were used for comparison with the standard error of the mean. Methods determining the relative gene expression levels were as described by Livak and Schmittgen (2001).

\section{mRNA In Situ Hybridization}

In situ hybridization was carried out as described by Takechi et al. (1999), with some modification. The developing seeds were collected from the pods at 3-12 DAP and fixed in 3.7\% $(v / v)$ formaldehyde and 5\% $(v / v)$ acetic acid, under a slight vacuum for 3-4 $\mathrm{h}$ at room temperature, rinsed, dehydrated, and embedded in Technovit 8100 resin (Heraeus Kulzer $\mathrm{GmbH}$ ). Sections were cut at $3 \mu \mathrm{m}$ on a Zeiss HM 360 microtome fitted with a tungsten-carbide knife, and transferred to poly-L-lysinetreated slides (Sigma). A cDNA fragment of $484 \mathrm{bp}$ corresponding to exon portions of the gene of interest was amplified and cloned in the pBluescript II KS (+) Plasmid (Fermentas). The antisense and sense probes were obtained from the linearized transcription vectors by in vitro transcription with T7 and SP6 RNA polymerase. The following primers were used for PCR amplification: Pv BAT93 MIPS F5'- GATTTGGCTATCAGGAGG-3' and Pv BAT93 MIPS R5'-GAAACTTGCCCTCATCTT3'. The 484 bp probes were labeled during in vitro 
transcription by the incorporation of Dig-11-UTP (DIG RNA Labeling Kit [SP6/T7], Roche). The sense strand probes were used to detect nonspecific binding. In situ hybridization was performed at $48^{\circ} \mathrm{C}$ overnight with $3 \mathrm{ng}$ mRNA probe in $5 \times$ Denhardt, $50 \%(v / v)$ formamide, $0.75 \mathrm{M} \mathrm{NaCl}, 5 \mathrm{mM}$ EDTA, $1 \mathrm{mg} \mathrm{ml}^{-1}$ salmon sperm DNA, and $50 \mathrm{mM}$ sodium phosphate. Post-hybridization washing at graded stringency $(4 \times \mathrm{SSC}, 1 \times \mathrm{SSC}$, and $0.5 \times$ SSC) was followed by immunodetection using an antidigoxigenine antibody conjugated to alkaline phosphatase (HNPP Fluorescent Detection Set, Roche). All glassware was sterilized and solutions were prepared in RNase-free conditions using DEPC-treated water. Photographic images were recorded with a differential interference contrast optic microscope (Nikon Eclipse E800, Japan).

\section{Results}

Isolation and Sequence Analysis of Full-Length Pv_BAT93 MIPS cDNA from Common Bean

In order to isolate the gene coding for MIPS from developing seeds, we performed 5'/3' RACE and RT-PCR on cDNA derived from developing seeds of common bean. The pairs of primers were designed on the basis of available bean EST sequences (GenBank accession CV538378) in the GenBank database (www.ncbi.nlm.nih.gov). A full length cDNA of $1,873 \mathrm{bp}$ (called Pv_BAT93 MIPS) was isolated and shown to contain an open reading frame (ORF) of $1,533 \mathrm{bp}$ encoding a polypeptide of 510 amino acids with a 78-bp 5'-untranslated region and a 262-bp 3'untranslated region. The putative polyadenylation signal sequence (AAAATAA) is present 40 bp upstream of the poly (A) tail. The nucleotide sequence of the Pv_BAT93 MIPS gene-coding region was compared with sequences of PvMIPSs (GenBank accession AJ853494) and PvMIPSr (GenBank accession U38920) in the GenBank database and showed a similarity of $87 \%$ and $81 \%$, respectively. Surprisingly, the ORF of the Pv_BAT93 MIPS sequence (GenBank accession FJ647022) is very similar (99\% identity) to PvMIPSv (GenBank accession FN356964).

Figure 1 shows that the deduced amino acid sequence of Pv_BAT93 MIPS cDNA has a 95\% identity with MIPS of G. max, $92 \%$ with PvMIPSs, $87 \%$ with PvMIPSr, $91 \%$ with MIPS of Medicago sativa, $89 \%$ with MIPS of Triticum aestivum, $88 \%$ with MIPS of $A$. thaliana and $77 \%$ with MIPS of Z. mays. Interestingly, the Pv_BAT93 MIPS polypeptide contains four highly conserved motifs: GWGGNNG (domain 1), LWTANTERY (domain 2), NGSPQNTFVPGL (domain 3), and SYNHLGNNDG (domain 4). The amino acid sequence of these four domains is identical to those of other plant MIPS (Fig. 1). These four domains are involved in MIPS protein binding and are essential for MIPS functions, such as cofactor $\mathrm{NAD}^{+}$ binding and reaction catalysis (Majumder et al. 1997).

Phylogenetic analysis divided the MIPS gene into clusters in accordance with taxonomic differentiation (Fig. 2). The phylogenetic tree obtained in the phylogenetic analysis of the MIPS genes showed two main branches. The first branch encompasses the sequence of monocots. Surprisingly, A. thaliana rooted with monocots species. The second branch includes the dicotyledonous species. This branch was split into two observable sub-branches. One sub-branch is formed by species in the order Fabales, such as G. max and P. vulgaris. The second sub-branch is formed by species in the order Solanales, such as $S$. tuberosum, Nicotiana tabacum, and Lycopersicon esculentum.

\section{Genomic Southern Analysis}

The genomic organization of the Pv_BAT93 MIPS gene was characterized using genomic DNA prepared from leaf tissues. Three restriction enzymes EcoRI, HindIII, and XbaI were used, followed by hybridization with the 484-bp probe generated by PCR using the coding sequence of Pv_BAT93 MIPS as a template (Fig. 3). Sequence analysis revealed that restriction sites for the different restriction enzymes used were absent in the cDNA sequence. The results showed that at least three stronger hybridizing bands were present in each lane under high stringency (Fig. 3). Fileppi et al. (2010) revealed the presence of one copy for PvMIPSs and PvMIPSv in the common bean genome. Due to the high degree of sequence similarity among PvMIPSv and Pv_BAT93 MIPS, we cannot exclude the presence of the same copies for PvMIPSv and Pv_BAT93 MIPS. The Southern blot analysis pattern obtained with Pv_BAT93 MIPS sequence suggests that only one copy for each MIPS gene (PvMIPSs, PvMIPSr, and PvMIPSv/ Pv_BAT93 MIPS) is present in the common bean genome. In addition, the presence of a fourth weaker hybridizing fragment obtained with the Pv_BAT93 MIPS probe suggests a possible presence of a fourth MIPS gene in the common bean genome with a low homology to other sequences.

Levels of Pv_BAT93 MIPS Transcripts in Organs and Developing Seeds of Common Bean

RT-PCR expression analyses were carried out to detect endogenous Pv BAT93 MIPS transcripts in different common bean organs and developing seeds. The results revealed the presence of $\mathrm{Pv}$ BAT93 MIPS transcripts in seeds, flowers, cotyledons and, in particular, in leaves, but no signal was observed in roots and stems (Fig. 4). The mRNA levels of PvMIPSs (GenBank accession AJ 853494) was up-regulated in seed tissues and present at low levels in 

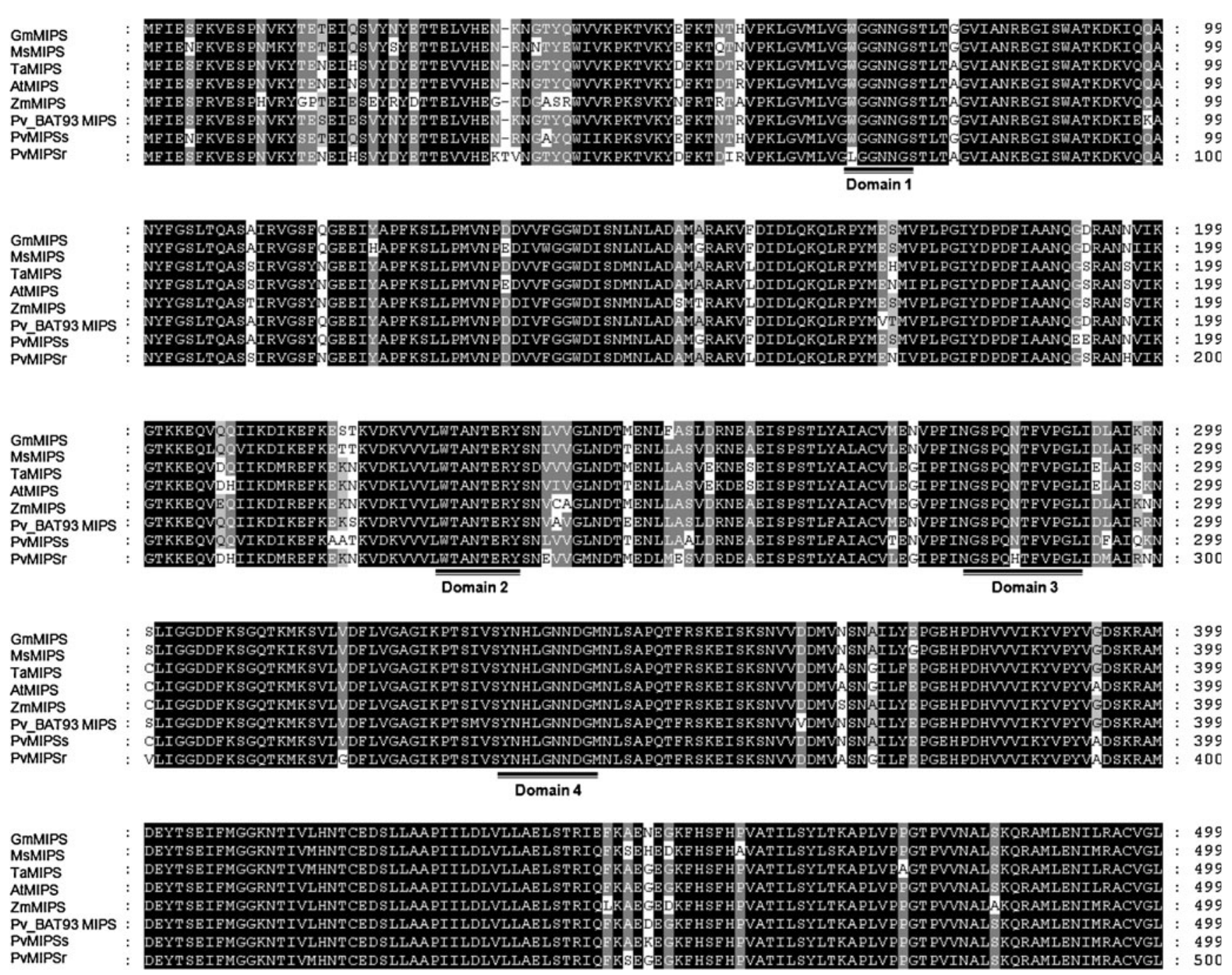

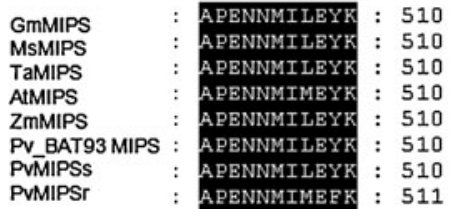

Fig. 1 Multiple alignment of representative plant myo-inositol phosphate synthase. GenBank database accession numbers of the displayed MIPS genes are as follows: GmMIPS G. $\max$ (cultivar Williams 82; ABC55421), MsMIPS M. sativa (subsp. falcata; ABO77439), TaMIPS T. aestivum (cultivar Fielder; AAD26330), AtMIPS A. thaliana (ecotype Columbia; AAD23618), ZmMIPS Z.

leaves, flowers, roots, and cotyledons, but no signal was observed in stems. A similar level of the $\mathrm{Pv} 18 \mathrm{~S}$ housekeeping gene was observed for all RT-PCR amplification (Fig. 4).

These data suggested that the two PvMIPS and Pv BAT93 MIPS genes are expressed in several of the organs examined but showed a difference in relative expression levels depending on the organ observed. mays (ACG33827), Pv BAT93 MIPS P. vulgaris (cultivar BAT93; ACN12926), PvMIPSs $P$. vulgaris MIPSs (cultuvar Taylor's Horticultural; CAH68559), PvMIPSr, P. vulgaris MIPSr (cultuvar Taylor's Horticultural; AAA91164). Bold underline indicates the putative domains

Therefore, MIPS genes have a spatially differential expression pattern in common bean.

Differential Expression of Pv_BAT93 MIPS cDNA in Wild-type and EMS Mutant Seed Development

In order to characterize MIPS gene during common bean seed development, real-time PCR analysis was carried out to examine 
Fig. 2 Bootstrap consensus phylogenetic tree of MIPS genes from plant species. The tree includes sequences of MIPS available in the GenBank and Tair databases. Abbreviation of the species and accession number of each sequence are: Pv BAT93 P. vulgaris (cultivar BAT93) (FJ647022), Gm G. max (cultivar Wye; AY038802), Vr V. radiata (cultivar KPS.1; EU239689), Pv P. vulgaris (cultivar Taylor's Horticultural; AJ853494), Nt N. tabacum (cultivar Xanthi nc; AB009881), At A. thaliana (ecotype Columbia; ATU04876), Ta T. aestivum (cultivar Biggar; AF120148), $\mathrm{Zm}$ Z. mays (EU961709), Hv H. vulgare (cultivar Harrington; AF056325), Os O. sativa (cultivar Kamenoo) (AB012107), Si $S$. indicum (cultivar Dan-Baek; AF284065), Citp C. paradisi (cultivar Marsh; Z32632), Le L. esculentum (AF293460), St S. tuberosum (cultivar Stirling; AF357837)

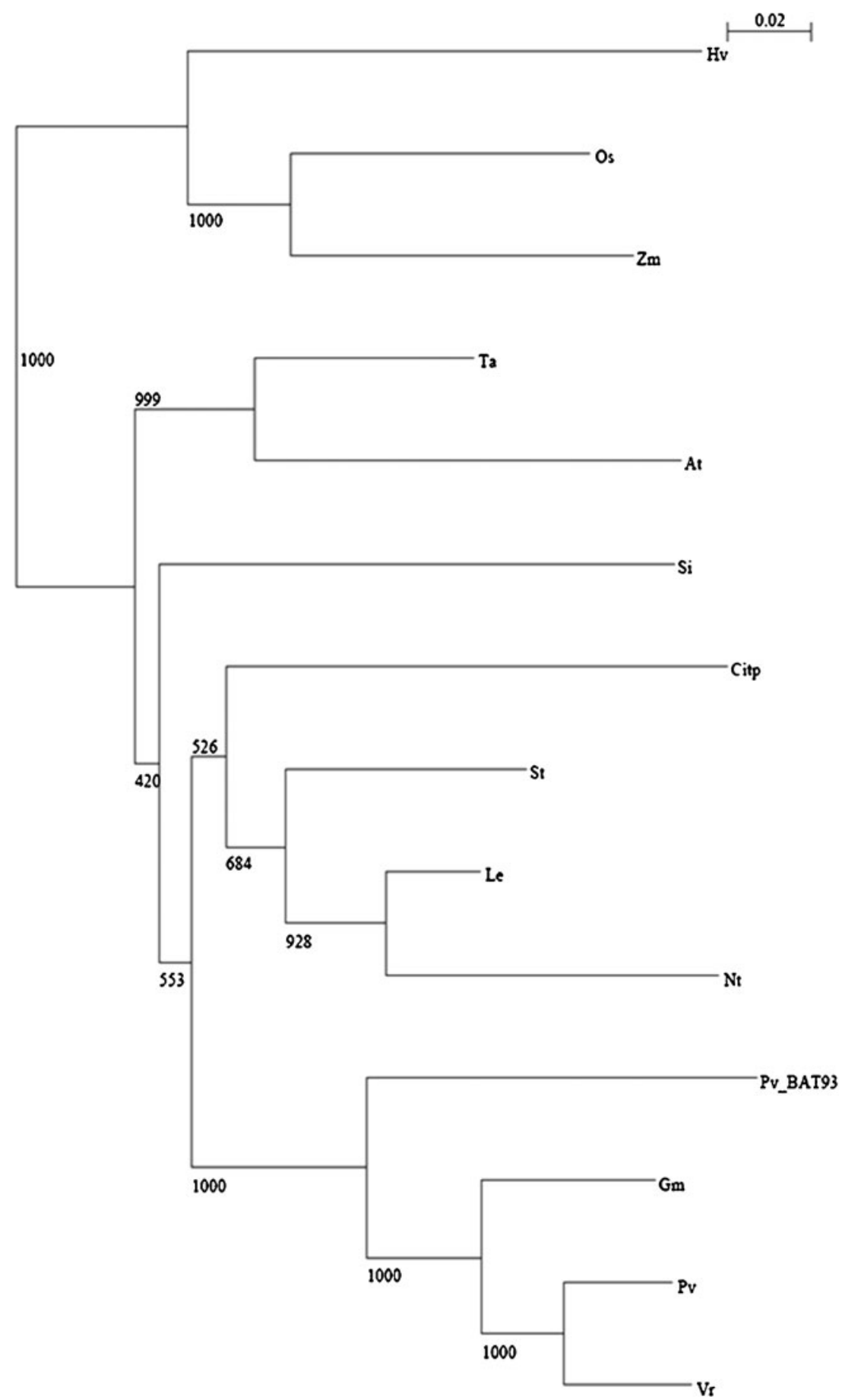

the expression of the Pv_BAT93 MIPS cDNA at different stages of seed development in wild-type and EMS mutant backgrounds. Seed development in the EMS mutant was considerably altered in growth and development compared with wild type (Fig. 5). After germination, we cannot see any significant differences in wild-type and EMS mutant seedling development (data not shown). Although, no considerable variation in morphology, flowering time, and fertility showed in EMS mutant compared with wild-type plant, the pattern of EMS mutant seed development showed disruption and lead to the embryo abortion. Mutant embryo defective seeds are readily distinguishable as shriveled and turned brown seeds from wildtype green seeds in immature pods (Fig. 5). Moreover, compared with wild type, all EMS mutant seeds are wrinkled and empty. Interestingly, similar phenotypes have been showed in Arabidopsis mips mutants (Donahue et al. 2010) which show a significant percentage of wrinkled and empty seeds compared with their corresponding wild-type accessions. 
Fig. 3 Genomic DNA gel blot analysis of MIPS. DNA gel blots containing $10 \mu \mathrm{g}$ of common bean genomic DNA digested with various restriction enzymes were hybridized with a radio-labeled MIPS probe (484 bp). E EcoRI, H HindIII, Xb XbaI. HindIII-digested bacteriophage $\lambda$ DNA was used as a size marker. Length markers are given on the left in kilobases

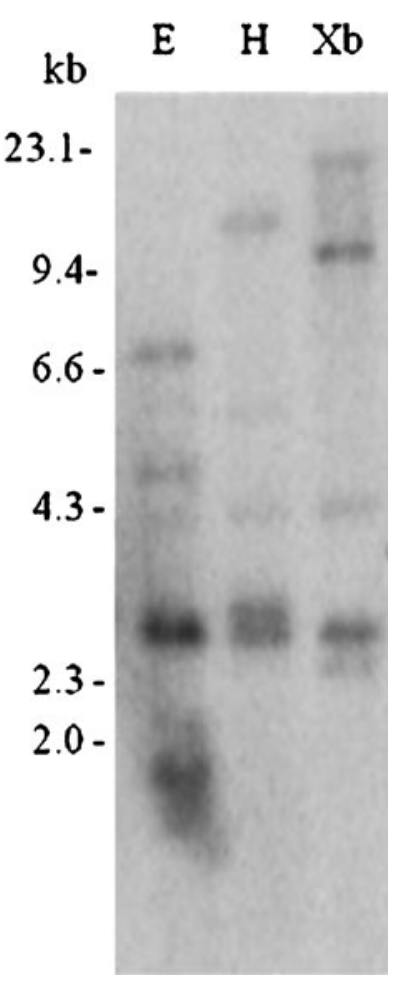

During wild-type embryogenesis (Fig. 6), the PV BAT93 MIPS expression became detectable on the third day after pollination (3 DAP). The expression level of the MIPS was very low at $6 \mathrm{DAP}$, and then increased rapidly, reaching maximal levels at 8 and 9 DAP before decreasing thereafter (12 DAP). These decreases in Pv BAT93 MIPS expression at 12 DAP could be explained by an increase of phytate concentration at a later stage of embryo development. Interestingly, these results are in agreement with the specific activity of the MIPS enzyme during seed development (Coelho et al. 2007). Our data indicate that Pv_BAT93 MIPS was differentially expressed at different stages of common bean seed development.

Compared with the wild type, the mRNA level of Pv BAT93 MIPS in the EMS mutant was very low, at 3, 8, and 12 DAP (Fig. 6) but reached a maximal level at 9 DAP.

\section{In Situ Hybridization Analysis}

To determine the cellular localization and temporal expression pattern of Pv BAT93 MIPS protein in common bean developing seed, in situ hybridization was performed on

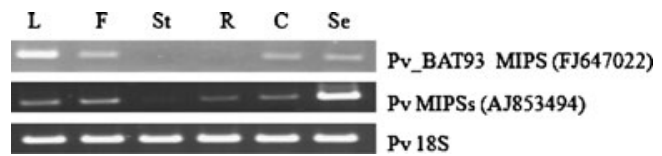

Fig. 4 RT-PCR of total RNA extracted from leaves $(L)$, flowers $(F)$, stems $(S t)$, roots $(R)$, cotyledons $(C)$, and seeds 15 DAP $(S e)$ using gene-specific primers for the PvMIPSs (AJ853494) and Pv BAT93 MIPS ( FJ647022). Lower lanes, $18 \mathrm{~S}$ is shown as a control
Fig. 5 Seeds phenotype of the wild-type and EMS mutant (15 DAP): a immature pod obtained by self-pollination of a wildtype plant. b Immature pod obtained by self-pollination of EMS mutant. Aborted seeds are indicated by arrowhead and are withered and dark brown

longitudinal sections of seeds with a DIG-labeled antisense RNA probe at 3, 6, 8, 9, and 12 DAP in wild-type and EMS mutant common bean (Fig. 7). The five points selected represent early, mid and late stages of seed development in common bean. For the wild type, the results showed that signals of the transcript appeared in the early globular stage embryo at 3 DAP (Fig. 7a). The signal was found in the maternal tissues (inner and outer integumentary layers), embryo proper, transfer cells and endosperm. At 6 DAP the

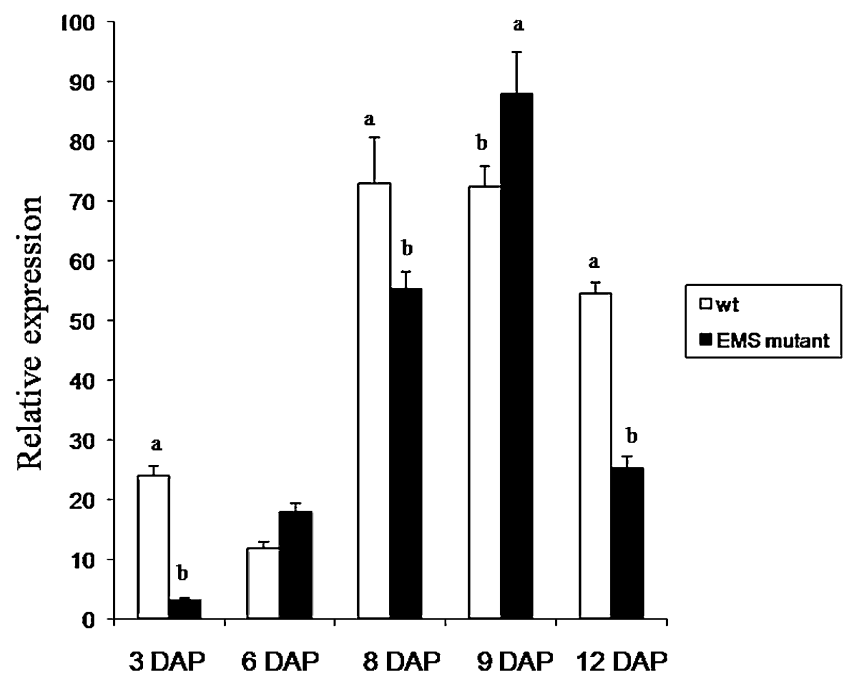

Fig. 6 Expression patterns of the MIPS gene in wild-type and EMS mutant seeds during common-bean seed development using real-time RT-PCR. The relative mRNA levels of individual Pv_BAT93 MIPS gene were normalized to housekeeping gene 18S. Data shown represent mean values obtained from three independent amplification reactions, and the errors bars indicate standard deviation. Significant difference $(P<0.05)$ detected by Tukey's multiple comparison test is shown by different letters above the bars 


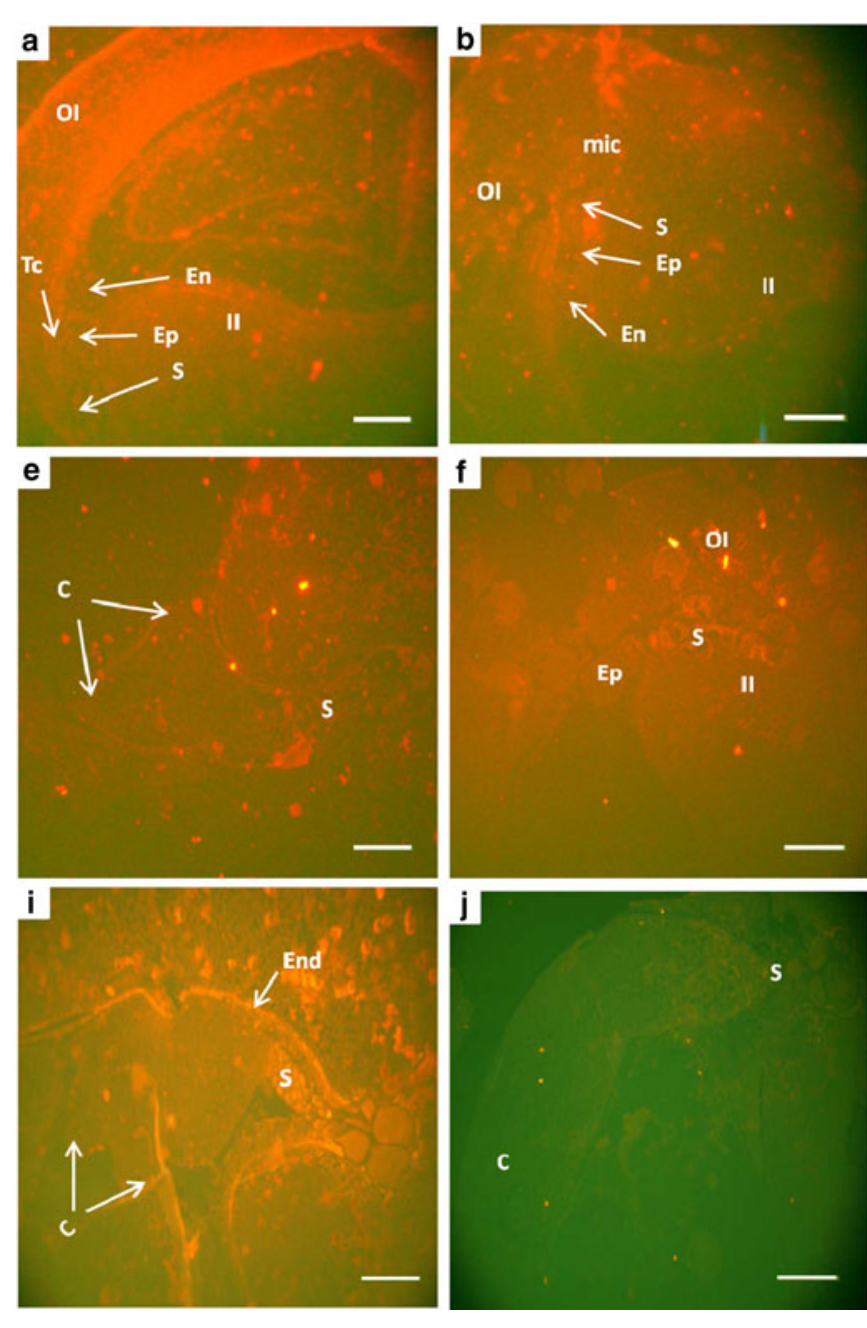

Fig. 7 MIPS in situ hybridization to longitudinal sections of common bean wild-type (a, c, e, g, i) and EMS mutant (b, d, f, h, j) seeds. MIPS antisense probe hybridized to seed sections with embryos at different developmental stages: 3 DAP, early globular stage (a, b); 6 DAP, globular stage (c, d); 8 DAP, heart stage $(\mathbf{e}, \mathbf{f})$; 9 DAP, torpedo

level of the transcripts decreased and signals were detected, particularly in suspensor and micropyle tissues (Fig. 7c), but we also detected signals in the embryo and endothelium. The level of the transcripts increased in the starchy maternal cells (inner integumentary layers) at 8 DAP (Fig. 7e). Accumulation of the Pv_BAT93 MIPS transcript was also observed in cotyledon cells. At 9 DAP, signals were detected in cotyledons, but a particularly strong localization signal was observed in the endothelium and in a group of cells located in the inner integumentary layer region near the micropyle (Fig. 7g). Pv BAT93 MIPS transcript expression decreased slightly at the bent cotyledon stage compared with the torpedo stages (Fig. 7i), but a high-intensity Pv BAT93 MIPS localization signal was detected in the suspensor and endothelium. At this stage, cells of the outer integument, adjacent to the micropyle, appeared larger and more vacuolated. We suggest that the level of
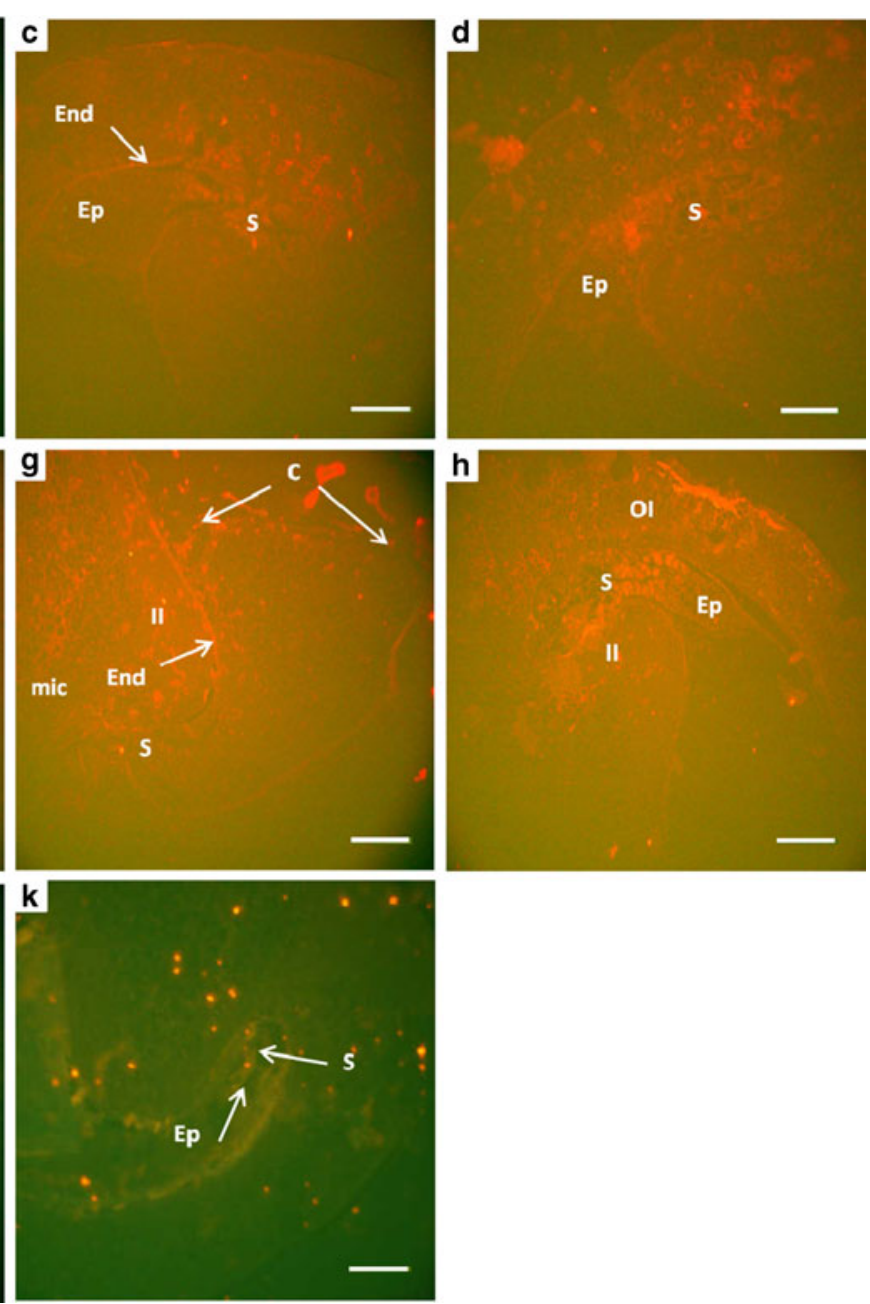

stage $(\mathbf{g}, \mathbf{h})$; and 12 DAP, bent cotyledon stage (i, j). Sense probe hybridized to seed sections with embryos at early globular stage (k). $C$ cotyledon, En endosperm, Ep embryo proper, End endothelium, II inner integument, mic micropyle, $O I$ outer integument, $S$ suspensor. Scale bars, $100 \mu \mathrm{m}$

the transcripts in the inner integumentary layers gradually decreased at 12 DAP.

In EMS mutant common bean, the suspensor showed dramatic evolution (the suspensor consisted of hypertrophic cells). The early globular stage contains a morphologically normal suspensor and embryo (Fig. 7b). Abnormal divisions in the suspensor first appear at the late globular stage (Fig. 7d) and continue during subsequent growth (Fig. 7f, h, j). Cell divisions continue in both the embryo and suspensor through the torpedo stage, resulting in an elongated embryo and a suspensor that is often the size of the embryo.

At the early globular stage (3 DAP), Pv BAT93 MIPS was expressed in embryo, suspensor and endosperm tissues, but a low signal was observed in the outer and inner integumentary layers (Fig. 7b) compared with the wild type. The level of the transcripts in embryo tissues gradually 
decreased at 6 DAP and a signal was observed, particularly in the suspensor. At 8 and 9 DAP, a signal was detected in the embryo and suspensor, but the localization signal was more intense at the interface between the suspensor and embryo proper (Fig. 7f, h). At the bent cotyledon stage (12 DAP) we did not reveal any background Pv_BAT93 MIPS signal in embryo tissues (Fig. 7j). Unlike the other stages of EMS mutant seed development, a localization signal for Pv_BAT93 MIPS was not detected in the outer and inner integumentary layers. Instead, a lower-intensity Pv_BAT93 MIPS localization signal was detected throughout the seed, including in the radical of the embryo. Pv_BAT93 MIPS expression at the EMS mutant cotyledon stage appeared to be eventually disrupted. No signal was detected in the control sections (Fig. 7k).

\section{Discussion}

Characterization of the Deduced Pv_BAT93 MIPS Protein

MIPS is a pivotal biosynthetic enzyme in the myo-inositol pathway, including the synthesis of phytic acid, and it plays important roles in some of the essential metabolic reactions in both eukaryotic and prokaryotic organisms (Majumder et al. 1997). MIPS coding sequences have been isolated (Hegman et al. 2001) and characterized by a temporally and spatially distinct expression pattern from a number of plant species, such as G. $\max$ (Nunes et al. 2006), S. indicum (Chun et al. 2003) and A. thaliana (Chiera and Grabau 2007). In some cases, two or three MIPS genes have been isolated from each species (Majumder et al. 2003).

In the present study, a cDNA encoding the enzyme was cloned from developing common bean seeds, and the expression patterns of Pv_BAT93 MIPS during common bean seed development were analyzed. Deduced amino acid sequences of the Pv_BAT93 MIPS cDNA showed high identity and similarity with sequences from MIPS $P$. vulgaris and other plant species (Fig. 1).

As discussed earlier (Chun et al. 2003), stretches of amino acid residues such as GWGGNNG, LWTANTERY, NGSPQNTFVPGL and SYNHLGNNDG are conserved in MIPS proteins of all eukaryotes. Figure 1 shows that the four highly conserved functional sequences are present in the Pv_BAT93 MIPS sequence. These four domains are involved in MIPS protein binding and are essential for MIPS functions, such as cofactor $\mathrm{NAD}^{+}$binding and reaction catalysis (Majumder et al. 1997; Norman et al. 2002). Figure 1 also predicted a conserved transmembrane motif (CEDSLLAAPIILDLVLLAELSTR), located about 68 amino acids from the C-terminus in both P. vulgaris and other species. The sequence analysis of the predicted
Pv_BAT93 MIPS indicated that the N-terminal region contains no signal for chloroplast transit or mitochondrial targeting peptides. However, the absence of a convincing transit peptide in Pv_BAT93 MIPS probably does not preclude its targeting to a plastidic site for inositol synthesis in common bean. Our hypothesis is supported by Lackey et al. (2003), who found that the P. vulgaris MIPS enzyme is present in plasma membranes, plastids, mitochondria, endoplasmic reticulum, nuclei, and cell walls although it does not have a recognizable transit peptide. This difference suggests different evolutionary processes. The phylogenetic tree constructed on the basis of multiple alignments of MIPS genes shows a clear segregation of these genes into monocotyledonous and dicotyledonous (Fig. 2). The amino acid sequence of Pv_BAT93 MIPS shows a high degree of similarity and is strongly clustered in a subgroup belonging to Fabales species. These data indicate that the genes encoding MIPS reveal remarkable evolutionary conservation of the primary structure (Majumder et al. 2003).

Genomic southern blot analysis showed that at least three MIPS genes are present in the common bean genome, indicating that common bean MIPS belonged to a small gene family, as in the case of the counterparts from some other plant species, such as Z. mays (Larson and Raboy 1999). Currently, three sequences encoding the P. vulgaris MIPS gene have been described. Several copies of the MIPS-encoding genes have been observed in the plant genome for most species, suggesting that each gene copy could be differentially controlled and expressed (Chiera and Grabau 2007). In A. thaliana, three MIPS genes were reported (Johnson and Sussex 1995; Mitsuhashi et al. 2008). Three were found in S. indicum (Chun et al. 2003), four in G. max (Hegman et al. 2001; Chappell et al. 2006), seven in Z. mays (Larson and Raboy 1999), and two MIPS genes encoding the RINO1 and RINO2 genes were present in the rice genome (Yoshida et al. 1999; Suzuki et al. 2007).

\section{Expression Profile of MIPS in Different Tissues of Common Bean}

Transcripts of the Pv_BAT93 MIPS gene were detected in seeds, cotyledons, flowers and leaves. No signal transcripts of Pv_BAT93 MIPS were revealed in stems or roots; this could be due to the relatively very low occurrence or absence of the biosynthesis of inositol or phytic acid in these tissues compared with developing seeds and leaves (Yoshida et al. 1999). The mRNA levels of the PvMIPSs gene were higher in developing seeds than in other tissues, including leaves, flowers, roots, cotyledons, and stems. These data demonstrate that the expression of both genes is organ specific and such differential regulation would coordinate inositol metabolism with cellular growth (Majumder et al. 1997). Our data 
suggested that the Pv_BAT93 MIPS gene might present a distinct pattern when compared with other plants. All three AtMIPS genes were expressed in developing seeds, leaves and roots (Mitsuhashi et al. 2008). However, in G. $\max$ MIPS1 is highly expressed in developing seeds and MIPS2 is expressed highest in roots, whereas MIPS3 and MIPS4 are expressed in several tissues, with their highest expression in leaves (Chappell et al. 2006). The expression patterns of MIPS in A. thaliana, G. max, and common bean suggest that transcriptional and translational mechanisms operate to regulate the temporal and spatial expression of MIPS in plant species.

Expression Profile of MIPS in Wild-type and EMS Mutant Common-Bean Seed Tissues

Various mutagenesis and screening approaches such as EMS, T-DNA insertion, genetic reverse, and genetic sense have been used to study the genes involved and required for embryo formation and development in A. thaliana, Z. mays, G. max, and O. sativa (Sheridan and Clark 1993; Hong et al. 1995). In this optic, we have used plants deficient in seed development from the EMS-mutagenized seeds of common bean (Silué et al. 2008).

Analysis of the Pv_BAT93 MIPS RNA level in common bean wild-type tissues showed a marked peak at 9 DAP, indicating that the gene is regulated at the transcriptional level during seed development. Similar results were observed in G. $\max$ (Chappell et al. 2006), Passiflora edulis (Abreau and Aragao 2007) and P. vulgaris (Coelho et al. 2007). The expression profile of Pv_BAT93 MIPS in common bean tissues showed a recognizable difference in the transcript level of Pv_BAT93 MIPS between different developmental stages of common bean seeds from 3 to 12 DAP. Interestingly, at 8 and 9 DAP we cannot show a difference in transcript level (Fig. 6). This expression pattern could be correlated with the accumulation of phytic acid, which is a storage reserve of phosphorus in seeds (Yoshida et al. 1999). We suggest that the accumulation of MIPS transcripts during the early stages of common-bean seed development must have a greater role not only in plant basic metabolism, but also during seed development.

The EMS mutant showed alteration in Pv_BAT93 MIPS gene transcription during seed development. The results revealed that Pv_BAT93 MIPS transcripts are downregulated at 3 DAP and up-regulated at 9 DAP, with a decrease at 12 DAP. In stress treatment such as salinity stress, mRNA MIPS accumulation is up-regulated after the initiation of the treatment, and the signal declined thereafter in O. sativa and Citrus sinensis (Yoshida et al. 2002). These results correspond with the rapid changes in inositol phosphates observed in different plant systems with many different stimuli, including osmotic, cold shock, light, abiotic, and biotic elicitors (Perera et al. 2006). The alteration of Pv_BAT93 MIPS expression in the EMS mutant could affect myo-inositol, and might also affect the phytic acid synthesis during the early stages of seed development. This alteration could therefore disrupt EMS mutant seed development. However, we do not know whether the MIPS gene is directly responsible for the observed mutation.

It should be noted that both genotypes (wild-type and EMS mutant common bean) were grown in the same greenhouse and the samples were harvested at almost the same time, thus minimizing the possible influences of environmental factors. In addition, although the two genotypes were not lineage related, there were no obvious developmental differences (such as flowering) between them. It is therefore unlikely that altered temporal program of Pv_BAT93 MIPS expression could be due to differences in either the environment or the breeding backgrounds.

Previous reports of alteration in MIPS expression in potato (Keller et al. 1998) and soybean (Nunes et al. 2006) show that the loss of the reduction of the tissue-specific gene products is due either to a mutation in a gene that encodes MIPS or to antisense inhibition. The results regarding EMS mutant seeds are unique because they indicate a regulatory type of change, as evidenced by an altered program of gene expression. Whether such a change in Pv_BAT93 MIPS expression is a cause or a feedback effect of a mutation in certain upstream regulatory genes (such as those encoding the transcription factors) remains to be elucidated.

\section{Roles for Pv_BAT93 MIPS in Common Bean Embryogenesis}

Using in situ hybridization techniques, the expression of the common bean Pv_BAT93 MIPS was characterized during early seed development in wild-type and EMS mutant common bean. The progress of morphogenesis in EMS mutant embryos was substantially delayed and abnormal, compared with wild-type embryos.

The Pv_BAT93 MIPS gene is expressed and follows different temporal profiles but with significant differences in the levels and sites of expression in wild-type and EMS mutant common bean. A limited amount of information about MIPS expression in common bean developing seed was known from previous analyses (Coelho et al. 2007). In developing soybean, MIPS expression was first detected in maternal tissues and then in the embryo (Chiera and Grabau 2007). However, in A. thaliana MIPS was shown to be restricted to the cytosol, primarily in the endosperm, during seed development and not in the embryo (Mitsuhashi et al. 2008). In developing monocotyledonous embryos such as rice, the analogous RINO1 transcript was first detected at 
the apex of the embryo and then in the scutellum and aleurone layers (Yoshida et al. 1999). In this study, unlike in other plant species, the expression of Pv_BAT93 MIPS occurred throughout development in the outer and inner integumentary layers, and was also evident in the embryo and suspensor at different stages of embryo development. Our data are similar to those suggesting that MIPS genes play a critical role in the early developmental stages of the embryo and this pattern expression should accompany synthesis and accumulation of phytic acid during seed development (Yoshida et al. 1999; Hegman et al. 2001; Chiera and Grabau 2007; Coelho et al. 2007; Mitsuhashi et al. 2008). The data also suggest that the expression of MIPS genes in this tissue at the early and late stages is important with regard to their function in embryogenesis.

In common bean, the expression of MIPS was detected at the globular and cotyledon stages of embryo development (Johnson and Wang 1996). Unquestionably, in the Fabaceae (legumes) such as the Phaseolus genus, the suspensors reached at full development or at maturity diverse and complexe morphological forms. The suspensor plays an active role in the absorption and translocation of nutriments essential for the growth of the embryo (Yeung and Sussex 1979). As also reported by Yeung (1980) and Nagl (1990), the expression of Pv_BAT93 MIPS at the proximity of the micropyle indicate that myo-inositol is exported to the embryo via the suspensor. In addition, a particularly distinct Pv_BAT93 MIPS localization pattern on one side of the micropyle, in a group of cells located in the inner integument, suggests that one of the major functions of these cells is probably to produce myo-inositol. Together, these data indicate that suspensor supply a large amount of the required myo-inositol for embryo development. In addition, Gomez et al. (2005) and Mitsuhashi et al. (2008) determined that myo-inositol was produced in maternal tissue, principally the seed coat, and transported to the embryo. In developing soybean embryos, the analogous GmMIPS-1 transcript was also detected in the micropylar and chalazal ends of the seed (Chiera and Grabau 2007). It was determined that assimilates passed through the chalazal process and the suspensor to the embryo and endosperm (Chamberlin et al. 1993).

The expression of the MIPS gene was more precocious and intense in the suspensors of aborted seed than in the normal seed at the heart and torpedo stage (Fig. 7e, f, g, h). In contrast, at the cotyledon stage Pv_BAT93 MIPS was also up-expressed in wild-type seeds, while it was not expressed in the EMS mutant whose embryos had not developed bent cotyledons (Fig 7i, j). These data suggest that such mechanisms are impaired in EMS mutant common bean. It will be interesting to determine the extent of assimilation of the cotyledon in EMS mutant seed compared with normal seed development.
Transcript accumulation of Pv_BAT93 MIPS is altered in the EMS mutant compared with the wild type at early and late stages of embryo development. The temporal and spatial patterns of accumulation of the MIPS transcript suggest that the gene could play a key role in common bean embryogenesis.

\section{Conclusions}

The present work leads to some interesting conclusions. We have successfully isolated and characterized a functional gene encoding MIPS involved in the biosynthesis of phytic acid from common bean during seed development. Multiple alignments showed that the deduced Pv_BAT93 MIPS gene had high identity with other plant MIPS, and contained conserved motifs of MIPSs. Expression pattern analysis showed that the transcripts of Pv_BAT93 MIPS are differentially expressed in the early stages of common bean seed development. Alteration of Pv_BAT93 MIPS expression in the EMS mutant is consistent with the idea that this enzyme was needed to maintain a higher level of inositol and phytic acid synthesis in normal developing seed tissues than in abortive seed tissues.

To develop a greater understanding of the role of MIPS during embryogenesis, tissue-specific localization of MIPS during seed development has been reported using in situ hybridization. Pv_BAT93 MIPS expression was shown here in embryo and maternal tissues, but was also identified in suspensor tissues during the early and late stages of seed development. The presence of phytic acid in embryo tissues implies an interaction between the tissues in the synthesis (maternal tissues), the suspensor and the subsequent storage (embryo) of phytic acid during seed development in common bean.

\section{References}

Abreau EFM, Aragao FJL (2007) Isolation and characterization of a myo-inositol-1-phosphate synthase gene from yellow passion fruit (Passiflora edulis f. flavicarpa) expressed during seed development and environmental stress. Ann Bot 99:285-292

Abu-abied M, Holland D (1994) Two newly isolated genes from citrus exhibit a different pattern of diurnal expression and light response. Plant Mol Biol 26:165-173

Adhikari J, Majumder AL, Bhaduri TJ, Dasgupta S, Majumder AL (1987) Chloroplast as a locale of L-myo-inositol 1-phosphate synthase. Plant Physiol 85:611-614

Bregitzer PP, Raboy V (2006) Effects of four independent low-phytate mutations on barely (Hordeum vulgare L.) agronomic performances. Crops Sci 46:1318-1322

Campion B, Sparvoli F, Doria E, Tagliabue G, Galasso I, Fileppi M, Bollini R, Neilsen E (2009) Isolation and characterization of an lpa (low phytic acid) mutant in common bean (Phaseolus vulgaris L.). Theor Appl Genet 118:1211-1221 
Chamberlin MA, Horner HT, Palmer RG (1993) Nutrition of ovule, embryo sac, and young embryo in soybean: an anatomical and autoradiographic study. Can J Bot 71:1153-1168

Chappell AS, Scaboo AM, Wu X, Nguyen H, Pantalone VR, Bilyeu KD (2006) Characterization of the MIPS gene family in Glycine max. Plant Breed 125:493-500

Chatterjee A, Dastidar KG, Maitra S, Das-Chatterjee A, Dihazi H, Eschrich K, Majumder AL (2006) sII1981, an acetolactate synthase homologue of Synechocystis sp. PCC6803, function as L-myo-inositol 1-phosphate synthase. Planta 224:367-379

Chiera JM, Grabau EA (2007) Localization of myo-inositol phosphate synthase (GmMIPS-1) during the early stages of soybean seed development. J Exp Bot 58:2261-2268

Chun JA, Jin UH, Lee JW, Yi YB, Hyung NI, Kang CW, Seo HY, Lee SW, Chung $\mathrm{CH}$ (2003) Isolation and characterization of a myoinositol 1-phosphate synthase cDNA from developing sesame (Sesamum indicum L.) seeds: functional and differential expression, and salt-induced transcription during germination. Planta $216: 874-880$

Coelho CMC, Benedito VA, Figueira A, Vitorello VA, Azevedo RA (2007) Variation in the enzyme activity and gene expression of myo-inositol-3-phosphate synthase and phytate accumulation during seed development in common bean (Phaseolus vulgaris L.). Acta Physiol Plant 29:265-271

Cullen PJ, Cozier GE, Banting G, Mellor H (2001) Modular phosphoinositide-binding domains - their role in signaling and membrane trafficking. Curr Biol 11:882-893

GhoshDastidar K, Chatterjee A, Majumder AL (2006) Evolutionary divergence of L-myo-inositol 1-phosphate synthase: significance of a "core catalytic structure". Subcell Bio-chem 39:315-340

Donahue JL, Alford SR, Torabinejad J, Kerwin RE, Nourbakhsh A, Ray WK, Hernick M, Huang X, Lyons BM, Hein PP, Gillaspy G (2010) The Arabidopsis thaliana myo-inositol 1-phosphate synthase 1 gene is required for myo-inositol synthesis and suppression of cell death. Plant Cell 22:888-903

Dorsch JA, Cook A, Young KA, Anderson JM, Bauman AT, Volkmann CJ, Murthy PPN, Raboy V (2003) Seed phosphorus and inositol phosphate phenotype of barley low phytic acid genotypes. Phytochemistry 62:691-706

Fileppi M, Galasso I, Tagliabue G, Daminati MG, Campion B, Doria E, Sparvoli F (2010) Characterisation of structural genes involved in phytic acid biosynthesis in common bean (Phaseolus vulgaris L.). Mol Breeding 25:453-470

Gomez CI, Obendorf RL, Horbowicz M (2005) Myo-inositol, D-chiroinositol, and D-pinitol synthesis, transport, and galactoside formation in soybean explants. Crop Sci 45:1312-1319

Guttieri MJ, Peterson KM, Souza E (2006) Agronomic performance of a low phytic acid wheat. Crop Sci 46:2623-2629

Hait NC, Ray Chaudhuri A, Das A, Bhattacharyya S, Majunder AL (2002) Processing and activation of chloroplast L-myo-inositol 1phosphate synthase from Oryza sativa requires signals from both light and salt. Plant Sci 162:559-568

Hatzack F, Johansen KS, Rasmussen SK (2000) Nutritionally relevant parameters in low-phytate barley (Hordeum vulgare L.) grain mutants. J Agr Food Chem 48:6074-6080

Hegman CE, Good LL, Grabau EA (2001) Expression of D-myoinositol phosphate synthase in soybean. Implication for phytic acid biosynthesis. Plant Physiol 128:650-660

Hong SK, Aoki T, Kitano H, Satoh H, Nagato Y (1995) Phenotypic diversity of 188 rice embryo mutants. Dev Genet 16:298310

Imhoff V, Bourdu R (1973) Formation d'inositol par les chloroplasts isolés de pois. Phytochemistry 12:331-336

Iqbal MJ, Afzal AJ, Yaegashi S, Ruben E, Triartayakorn K, Njiti VN, Ahsan R, Wood AJ, Lightfoot DA (2002) A pyramid of loci for partial resistance to Fusarium solani f. sp. glycines maintains myo-inositol-1-phosphate synthase expression in soybean roots. Theor Appl Genet 105:1115-1123

Johnson MD (1994) The Arabidopsis thaliana myo-inositol 1phosphate synthase (EC 5.5.1.4). Plant Physiol 105:1023-1024

Johnson MD, Sussex IM (1995) 1-L-Myo-inositol 1-phosphate synthase from Arabidopsis thaliana. Plant Physiol 107:613-619

Johnson MD, Wang X (1996) Differentially expressed forms of 1-Lmyo-inositol-1-phosphate synthase (EC 5.5.1.4) in Phaseolus vulgaris. J Biol Chem 27:17215-17218

Keller R, Brearley CA, Trethewey RN, Müller-Röber B (1998) Reduced inisitol content and altered morphology in transgenic potato plants inhibited for 1D-myo-inositol 3-phosphate synthase. Plant J 16:403-410

Kuwano M, Ohyama A, Tanaka Y, Mimura T, Takaiwa F, Yoshida KT (2006) Molecular breeding for transgenic rice with low-phyticacid phenotype through manipulating myo-inositol 3-phosphate synthase gene. Mol Breed 18:263-272

Larson SR, Raboy V (1999) Linkage mapping of maize and barley myo-inositol 1-phosphate synthase DNA sequences: correspondence with a low phytic acid mutation. Theor Appl Genet 99:2736

Larson SR, Rutger JN, Young KA, Raboy V (2000) Isolation and genetic mapping of a non-lethal rice (Oryza sativa L.) low phytic acid 1 mutation. Crop Science 40:1397-1405

Lackey KH, Pope PM, Johnson MD (2003) Expression of 1L-myoinositol-1-phosphate synthase in organelles. Plant Physiol 132:2240-2247

Livak KJ, Schmittgen TD (2001) Analysis of relative gene expression data using real-time quantitative PCR and $2^{-\Delta \Delta C T}$ method. Methods 25:402-408

Luo Y, Qin G, Zhang J, Liang Y, Song Y, Zhao M, Tsuge T, Aoyama T, Liu J, Gu H, Qu LJ (2011) D-Myo-inositol-3-phosphate affects phosphatidylinositol mediated endomembrane function in Arabidopsis and is essential for auxin-regulated embryogenesis. Plant Cell 23:1352-1372

Majumder AL, Johnson MD, Henry SA (1997) 1L-myo-inositol 1phosphate synthase. Acta Biochim Biophys 1348:245-256

Majumder AL, Chatterjee A, GhoshDastidar K, Majee M (2003) Diversification and evolution of L-myo-inositol 1-phosphate synthase. FEBS Lett 553:3-10

Majee M, Maitra S, Dastidar KG, Pattnaik S, Chatterjee A, Hait NC, Das KP, Majumder AL (2004) A novel salt-tolerant L-myoinositol-1-phosphate synthase from Porteresia coarctata (Roxb) Tateoka, a halophytic wild rice: molecular cloning, bacterial overexpressing, characterization, and functional introgression into tobacco conferring salt tolerance phenotype. J Biol Chem 279:28539-28552

Meis SH, Fehr WR, Schnebly SR (2003) Seed source effect on field emergence of soybean lines with reduced phytate and raffinose saccharides. Crop Sci 43:1336-1339

Murray MG, Thompson WF (1980) Rapid isolation of high molecular weight plant DNA. Nucleic Acids Res 8:4321-4326

Mitsuhashi N, Kondo M, Nakaune S, Ohnishi M, Hayashi M, Hara-Nishimura I, Richardson A, Fukaki H, Nishimura M, Mimura T (2008) Localization of myo-inositol-1-phosphate synthase to the endosperm in developing seeds of Arabidopsis. J Exp Bot 59:3069-3076

Nagl W (1990) Translocation of putrescine in the ovule, suspensor and embryo of Phaseolus coccineus. J Plant Physiol 136:587-591

Nunes AC, Vianna GR, Cuneo F, Amaya-Farfan J, Capdeville G, Rech EL, Aragao FJL (2006) RNAi-mediated silencing of the myo-inositol-1-phosphate synthase gene (GmMIPS1) in transgenic soybean inhibited seed development and reduced phytate content. Planta 224:125-132

Norman RA, McAlister MS, Murray-Rust J, Movahedzadeh F, Stoker NG, McDonald NQ (2002) Crystal structure of inositol 1- 
phosphate synthase from Mycobacterium tuberculosis, a key enzyme in phosphatidylinositol synthesis. Structure 10:393-402

Parthasarathy R, Eisenberg F (1986) The inositol phospholipids: a stereochemical view of biological activity. Biochem J 235:313-322

Perera IY, Hung CY, Brady S, Muday GK, Boss WF (2006) A universal role for inositol 1,4,5-triphosphate kinase in transcriptional control. Science 287:2026-2029

Pilu R, Landoni M, Cassani E, Doria E, Nielsen E (2005) The maize lpa241 mutation causes a remarkable variability of expression and some pleiotropic effects. Crop Sci 45:2096-2105

Raboy V, Gerbasi PF, Young KA, Stoneberg SD, Pickett SG, Bauman AT, Murthy PP, Sheridan WF, Ertl DS (2000) Origin and seed phenotype of maize low phytic acid 1-1 and low phytic acid 2-1. Plant Physiol 124:355-368

Rozen S, Skaletsky HJ (2000) Primer3 on the WWW for general users and for biologist programmers. In: Krawetz S, Misener S (eds) Bioinformatics methods and protocols: methods in molecular biology. Humana, Totowa, pp 365-386

Sheridan WF, Clark JK (1993) Mutational analysis of morphogenesis of the maize embryo. Plant J 3:347-358

Silué S, Lariguet P, Pankhurst C, Jacquemin JM, Broughton WJ, Baudoin JP (2006) Screening Phaseolus vulgaris L. EMS mutants to isolate plants which failed in seed development. Annu Rep Bean Improv Coop 49:149-150

Silué S, Jacquemin JM, Lariguet P, Pankhurst C, Broughton WJ, Baudoin JP (2008) Characterization of Phaseolus vulgaris L. EMS mutant failing in seed development. Bean Improv Coop 51:50-51

Stevenson-Paulik J, Bastidas RJ, Chiou S, Frye RA, York JD (2005) Generation of phytate-free seeds in Arabidopsis through disruption of inositol polyphosphate kinases. PNAS 102:12612-12617
Suzuki M, Tanaka K, Kuwano M, Yoshida KT (2007) Expression pattern of inositol phosphate-related enzymes in rice (Oryza sativa $\mathrm{L}$.): implications for the phytic acid biosynthetic pathway. Gene 405:55-64

Takechi K, Sakamoto W, Katsuhara M, Murata M, Motoyoshi F (1999) In situ RNA hybridization using Technovit resin in Arabidopsis thaliana. Plant Mol Biol Rep 17:43-51

Torabinejads J, Gillaspy GE (2006) Functional genomics of inositol metabolism. Subcell Biochem 39:47-70

Wang X, Johnson MD (1995) An isoform of 1L-myo-inositol 1phosphate synthase (EC 5.5.1.4) from Phaseolus vulgaris. Plant Physiol 110:336

Wilcox JR, Premachandra GS, Young KA, Raboy V (2000) Isolation of high seed inorganic P, low-phytate soybean mutants. Crop Sci 40:1601-1605

Wongkaew A, Nakasathien S, Srinives P (2010) Isolation and characterization of D-myo-inositol-3-phosphate synthase from Mungbean (Vigna radiata). Plant Mol Biol Rep 28:122-127

Yeung EC (1980) Embryogeny of Phaseolus: the role of the suspensor. Z Pflanzenphysiol 96:17-28

Yeung EC, Sussex IM (1979) Embryogeny of Phaseolus coccineus: the suspensor and the growth of the embryo-proper in vitro. $\mathrm{Z}$ Pflanzenphysiol 91:423-433

Yoshida K, Fujiwara T, Naito S (2002) The synergetic effects of sugar and abscisic acid on myo-inositol-1-phosphate synthase expression. Physiologia Plantarium 114:581-587

Yoshida KT, Wada T, Koyama H, Mizobuchi-Fukuoka R, Naito S (1999) Temporal and spatial patterns of accumulation of the transcript of myo-inositol-1-phosphate synthase and phytincontaining particles during seed development in rice. Plant Physiol 119:65-72 